\title{
A Simulation Researchand Motion Control of Dental Chair in the Medical Application
}

\author{
P Ajay kalian, R. Puviarasi,MrithaRamalingam
}

\begin{abstract}
Generally, in hospitals the dental chair can be operated forward/backward for the treatment of the patients which is operated by human. Sometimes the chair will not function properly due to piston rust and over weighted patient and the dentist may have pain in the legs due to continuous operation of the chair. A voice controlled dental chair is designed to overcome these problems. It works on the commands given by the dentist. The voice modules are converted into machine understandable codes by attaching an Arduino. Arduino acts as an intermediate between the software and the hardware modules. Gas cylinders are responsible for the movement of the chair. The chair moves up and down as the pressure is accumulated on the chair by the release of the gas. A pressure gauge is attached to the gas cylinder and a solenoid valve is attached to it. All these work in a synchronous manner. If they don't work in synchronous manner the movement of chair is not in a linear manner. Gas cylinders extend and retract a piston rod to provide a push or pull force to drive the external load along a linear manner.
\end{abstract}

\section{INTRODUCTION}

This model is conceived an idea to ease the work of doctors who are using dental chair which consist of piston. Using voice controlled system for controlling the movement of the dental chair, it is to demonstrate that it can be a special idea that would stand separated from whatever is being used for the normal undertakings. The utilization of this new innovation in added with a mechanical framework keeping in mind the end goal to rearrange regular daily existence and it would start enthusiasm for a consistently developing present day society [1-4]. The problem is that sometimes the chair will not function properly due to piston rust and over weighted patient so the dentist may have pain in the legs due to continuous operation of the chair. So a voice controlled dental chair is made which will work naturally on the charges from the client for development reason and which is not available commercially. The cost adequacy of the framework makes it reasonable for the specialists to utilize. The system has a simple design.

The programmed discourse acknowledgment framework composed in this paper enables the dental chair to get input from a mike and the dental chair moves as indicated by the given piston. The dentist can just control the dental chair by his voice to move upward and downward. The module perceives the voice and sends control messages to the

Revised Manuscript Received on August 19, 2019.

P Ajay kalian, Department of Electronics and Communication Engineering, Saveetha School of Engineering, Saveetha Institute of Medical and Technical Sciences, Chennai. T.N, India

Dr. R. Puviarasi, Department of Electronics and Communication Engineering, Saveetha School of Engineering, Saveetha Institute of Medical and Technical Sciences, Chennai.T.N, India

MrithaRamalingam, Faculty of computer systems and software engineering, Universiti Malaysia Pahang Kuantan, Malaysia. microcontroller [5]. The proposed module acknowledgment based dental chair operation allows dentist to control the dental chair easily without the use of his hands and any physical pressure. The movement of the dental chair is controlled by the piston connected to the chair and drive framework which comprises of microcontroller and motor driving. On getting the Signal the microcontroller coordinates the piston through the control circuit. The code is written in Arduino such that the speed of the piston is controlled by using output pins of Arduino. A voice recognition system is easy to use and it is programmed so that the dentist can control the chair with ease. The primary words are recorded and stored using the program and feed to the Arduino. This is most valuable for the dental hospitals where they can move their dental seat in their own ways, with no outsider's help or support. Voice technology is used to reduce physical effort of the dentist. A voice module is used to perform voice controller actions. The system has been planned and executed in a financially way so that it can be used by any dentists and our work on this project is popularized. If this was implemented further it can be a great innovative revolution.

\section{BLOCK DIAGRAM OF VOICE CONTROLLED DENTAL CHAIR}

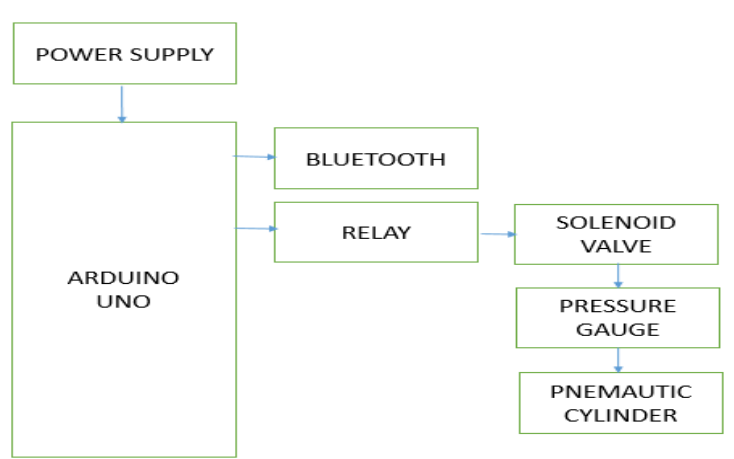

Fig 1: Block Diagram of proposed system

The Fig-1 denotes the basic block diagram of the voice controlled dental chair. It consists of a chair and the hardware mechanism. Arduino acts as an interface between the hardware mechanism and the chair. The hardware mechanism consists of a relay, solenoid valve, pressure gauge and a gas cylinder. An LCD display can also be used to check the functioning of the chair. 


\section{TOOLS USED}

\section{ARDUINO:}

The Arduino is the core part of the voice controlled dental chair. It contains all equipment's that are needed to support the microcontroller. "Uno" means one in Italian and is named to mark the upcoming release of Arduino. The pictorial representation of the Arduino is shown below in the fig-2.

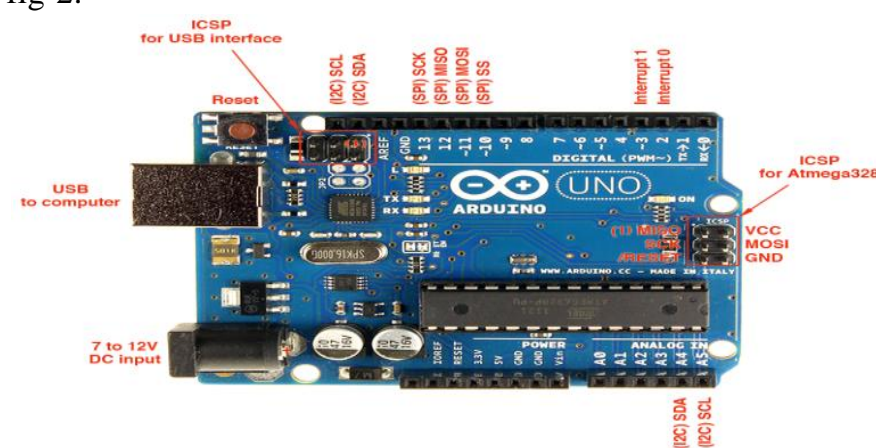

Fig 2: Arduino board

\section{Voice Recognition Module:}

Voice recognition is the method of changing the speech signal to a sequence of word. The speech signals are recorded in the external SRAM which is attached to the IC with the help of a directly connected microphone.

\section{PROGRAMMING:}

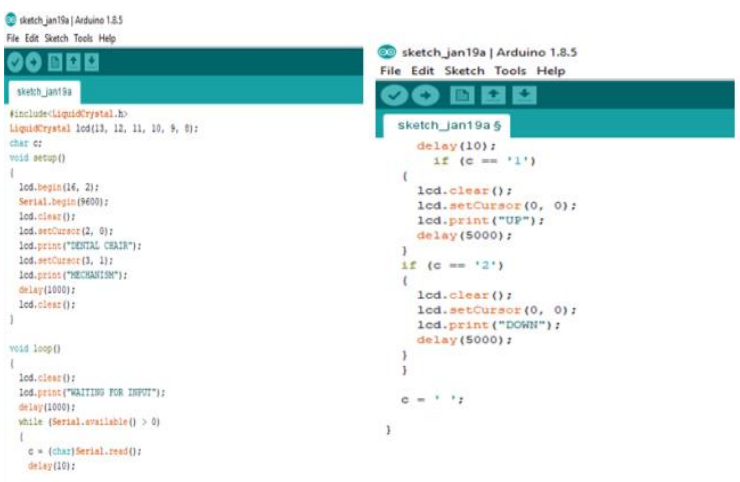

Fig 3: Program for LCD display

\section{EXPLANATION}

The above program is used to indicate the voice command of the dentist. The commands are displayed in the LCD screen.

The input pins are initialized in the primary part of the program. In the above program pins $13,12,11,10,9,8$ are used for both input and output. The numbers indicates the pin configuration of the Arduino. When the input is taken the commands will be compared with the pre-loaded commands. If the commands matches, it will be displayed in the screen. If the wrong command is given it shows a command of INVALID. The piston will work depending on the commands given.

The pointer in the LCD is initialized so that the text to be displayed is placed in the given pointer. The LCD is cleared all the time whenever a new command is given. Generally an LCD display system has 3 places to display the text. If the cursor is placed at $1^{\text {st }}$ position, it will display the text in $1^{\text {st }}$ position.

\section{WORKING PRINCIPLE}

The speech provided by the dentist is converted to sequence of words. These words are compared with the initialized words. For this mechanism to function, it requires 2 commands UP and DOWN. When the UP command is pronounced, the chair starts to move UP. When the DOWN command is pronounced, the chair moves DOWN

Suppose if the UP is pronounced, this speech signals are converted to sequence of words. As this word is already initialized, it gets compared with the initialized one. Once it gets matched with the given word it starts to move which is the required output of this project. The same is displayed in the screen. If any other word is pronounced, it will be compared with the initialized words. As the pronounced word is not the required word, it will show a warning as INVALID. There will be no movement in the chair.

\section{RESULTS}

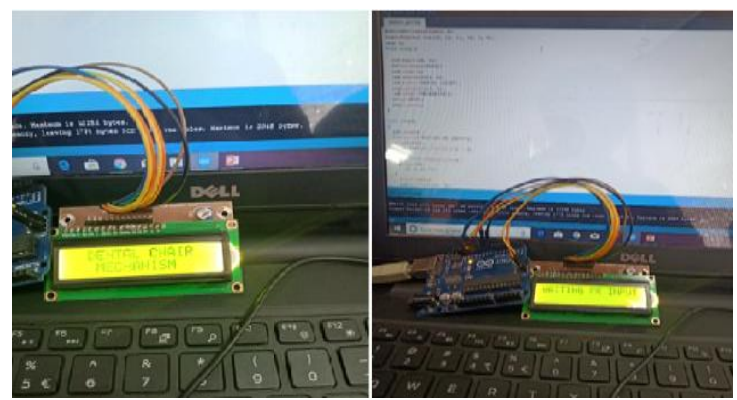

Fig 4: Display of commands in LCD

Fig-4 is used to show how the commands are displayed in the LCD. The first picture helps us to know that the Arduino is initialized. The second picture is used to indicate that the Arduino is ready to get the input.

\section{CONCLUSION}

This paper helps to construct a voice controlled dental chair using Arduino. The primary advantage of this chair is to reduce the physical work of the dentist and cost efficient. It is the best way to reduce the strain of doctors. With the help of proper circuit designing and programming most efficient dental chair can be obtained.

\section{REFERENCES}

1. Apsana.S1, Renjitha G Nair2, Voice Controlled Wheelchair using Arduino, Student ME, Dept. of Electronics \& Communication, MCET, Nedumangadu, Kerala, India1 Asst. Professor, Dept. of Electronics \& Communication, MCET, Nedumangadu, Kerala, India2, IARJSET ISSN (Online) 2393-8021 ISSN (Print) 2394-1588.

2. KharkaBahadur Rai1, Jeetendra Thakur2, Nirmal Rai3, voice controlled wheel chair using Arduino1, 2 Student, 3Asst. Professor, Department of Electronics and Communication Engineering, Sikkim Manipal Institute of Technology (SMIT), RangpooMajhitar, East Sikkim (India). International Journal of Science, Technology \& Management www.ijstm.com Volume No.04, Issue No. 06, June 2015 ISSN (online): 2394-1537

3. Prof. D.S.Nikam1, Joshi Gauri2, Shinde Mohini3, Tajanpure Mohini4, Wani Monika5 1,2,3,4,5, Voice Controlled Wheelchair Using AVR, Department of Electronics and telecommunication, SIER International Journal of Modern Trends in Engineering and

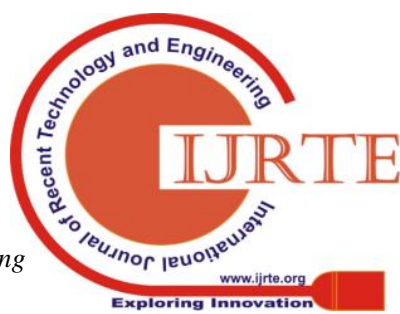


Research. E-ISSN: 2349-9745 p-ISSN: 2393-8161.

4. Smita u. Upase, 2a. K. Joshi, voice operated wheelchair for physically challenged people, 1,2Instrumentation and control Engineering Department CCOEW Pune, International Journal of Advances in Science Engineering and Technology, ISSN: 2321-9009, Vol-4, Iss-3, Spl. Issue-1 Aug.-2016

5. Anoop.K.J1, Inbaezhilan2, Sathish raj3, Ramaseenivasan4, CholaPandian5, Designing and Modelling of Voice Controlled Wheel Chair Incorporated with Home Automation, International Journal of Advanced Research in Electrical, Electronics and Instrumentation Engineering (An ISO 3297: 2007 Certified Organization) Vol. 3, Special Issue 2, April 2014. 